
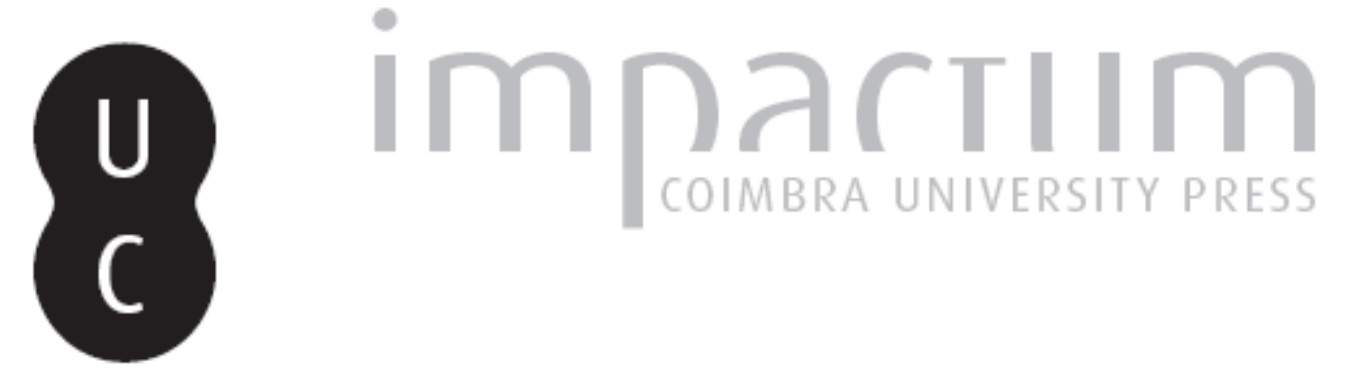

\title{
Serviço Público de Media e políticas públicas no contexto do sistema dos media português: 2003-2013
}

Autor(es): $\quad$ Conde, Nuno

Publicado por: Imprensa da Universidade de Coimbra

URL

persistente:

URI:http://hdl.handle.net/10316.2/39188

DOI:

DOI:http//dx.doi.org/10.14195/2183-6019_2_6

Accessed : $\quad$ 26-Apr-2023 13:21:59

A navegação consulta e descarregamento dos títulos inseridos nas Bibliotecas Digitais UC Digitalis, UC Pombalina e UC Impactum, pressupõem a aceitação plena e sem reservas dos Termos e Condições de Uso destas Bibliotecas Digitais, disponíveis em https://digitalis.uc.pt/pt-pt/termos.

Conforme exposto nos referidos Termos e Condições de Uso, o descarregamento de títulos de acesso restrito requer uma licença válida de autorização devendo o utilizador aceder ao(s) documento(s) a partir de um endereço de IP da instituição detentora da supramencionada licença.

Ao utilizador é apenas permitido o descarregamento para uso pessoal, pelo que o emprego do(s) título(s) descarregado(s) para outro fim, designadamente comercial, carece de autorização do respetivo autor ou editor da obra.

Na medida em que todas as obras da UC Digitalis se encontram protegidas pelo Código do Direito de Autor e Direitos Conexos e demais legislação aplicável, toda a cópia, parcial ou total, deste documento, nos casos em que é legalmente admitida, deverá conter ou fazer-se acompanhar por este aviso.

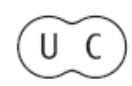


revista de comunicação,

jornalismo e espaço público

2

Periodicidade

Semestral

Imprensa da Universidade de Coimbra Coimbra University Press

\section{mediapolis}

tema

os desafios dos media

de serviço público

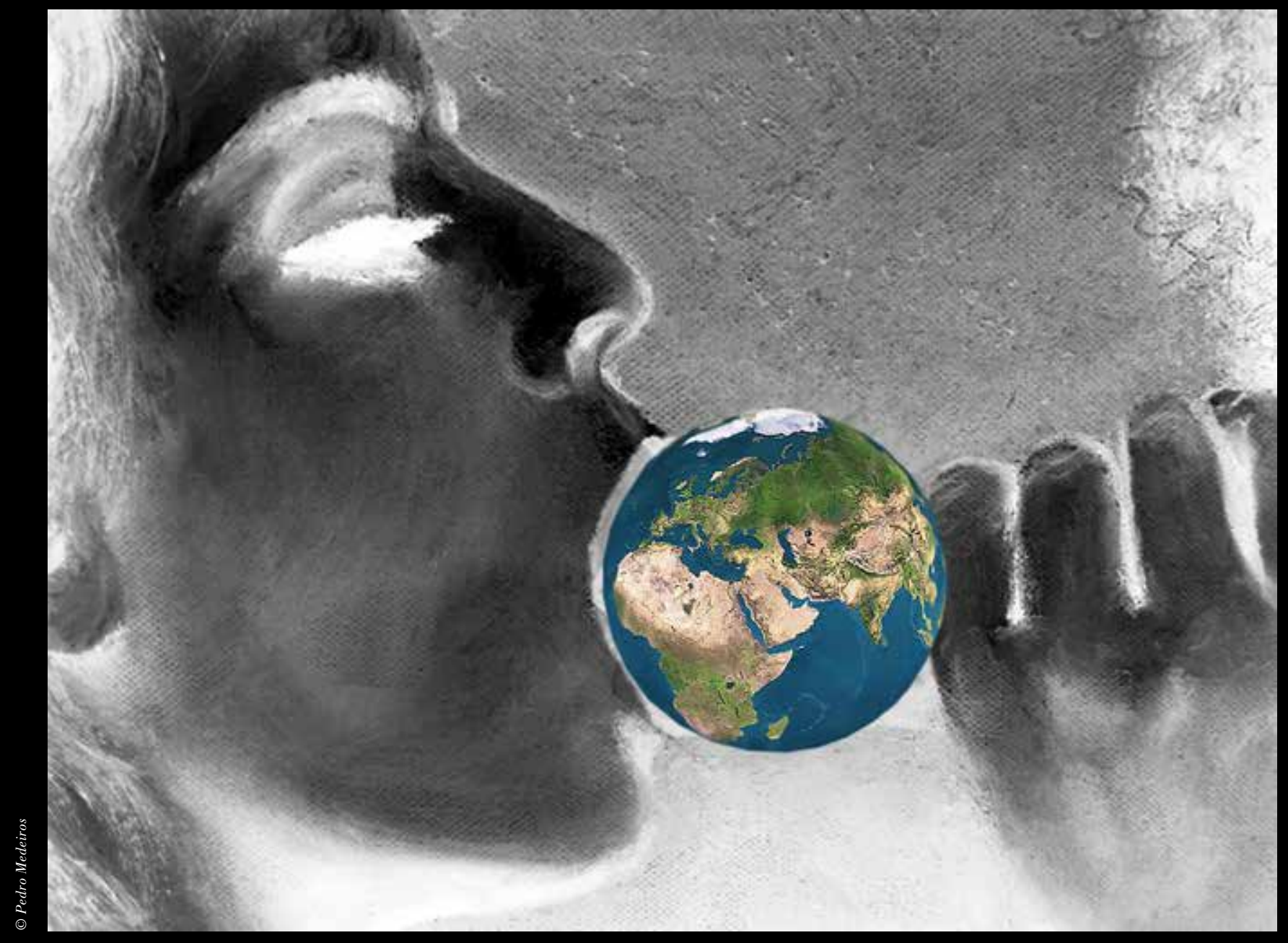




\title{
Serviço Público de Media e políticas públicas \\ no contexto do sistema dos media português: 2003-2013 \\ Nuno Conde \\ Centro de Estudos de Comunicação e Cultura (CECC \\ Universidade Católica Portuguesa \\ nuno.miguel_conde@gmail.com
}

\author{
Public service media and public policies \\ in the Portuguese media system context: 2003-2013
}

Resumo:

A presente comunicação tem por objeto a análise dos modelos de financiamento, governação e prestação de contas do serviço público de media em Portugal, entre 2003 e o último trimestre de 2013. As conclusões da investigação apontam para a redução progressiva do financiamento público da RTP, em sintonia com uma tendência mais vasta de reposicionamento do papel do Estado na sociedade. Constata-se que o Estado, enquanto acionista da RTP, perpetuou até ao momento um modelo de governação 'governamentalizado', no qual é patente a existência de um significativo grau de ligação entre o sistema político e o operador de serviço público. Reconhece-se, ainda, que os mecanismos institucionais de prestação de contas da RTP, relativamente ao cumprimento da sua missão de serviço público, têm como destinatário principal o Estado, em detrimento de práticas de prestação de contas mais direcionadas para o cidadão e para os restantes agentes do sistema de media.

Palavras-chave: Democracia, financiamento, modelo de governação, regulação, RTP, serviço público de media.

\section{Abstract:}

This article aims to analyze funding, governance and accountability models of public service media in Portugal, between 2003 and the last quarter of 2013. The research findings point to the progressive reduction of public funding for RTP, in line with a broader trend of repositioning the role of the state in society. It appears that the State as RTP's shareholder perpetuated a 'governmentalized' governance model, in which it is clear that there is a significant degree of connection between the political system and the public service operator. Furthermore, it recognizes that the institutional mechanisms of accountability in RTP, for the fulfillment of its public service mission, are primarily addressed to the State at the expense of practices to provide more targeted accounts for the citizen and for the other agents of the media system.

Keywords: Democracy, funding, governance, public service media, regulation, RTP.
1 Artigo escrito no âmbito de projeto de investigação «Grupos de Media do Atlântico Sul. Singularidades da Modernidade Lusófona», financiado pela FCT. Referência do projeto: EXPL/IVC-COM/1691/2012. 
O debate na esfera pública sobre os modelos ideais de serviço público de rádio e televisão, designadamente, a problemática da legitimidade e independência perante os poderes político e económico, âmbito da missão e modalidades de financiamento do serviço público, assume uma natureza essencialmente normativa, ancorada em valores sociopolíticos (Humphreys, 1996; Lowe \& Berg, 2013; Nord \& Glowacki, 2010) e ideológicos (Jakubowicz, 2008ª).

A compreensão da realidade complexa que constitui o conceito de serviço público de rádio e televisão ou, na aceção mais abrangente e tecnologicamente neutra, de serviço público de comunicação (Collins, 2010; Tambini e Cowling, 2004), serviço público de conteúdos (Torres, 2011), ou serviço público de media (Bardoel \& Lowe, 2008; Iosifidis, 2011; Jakubowicz, $\left.2008^{a}\right)$, passa em parte pela análise do papel do Estado enquanto agente modulador do sistema de media (Hallin \& Mancini, 2010), em particular, a sua intervenção enquanto proprietário, financiador e regulador do serviço público.

No caso Português, a discussão sobre o modelo de serviço público de rádio e televisão tem sido um tema recorrente durante o regime democrático, após 1974, e com uma particular incidência no período subsequente à abertura da atividade televisiva aos operadores comerciais, em 1992. A RTP, enquanto instituição que atua proativamente no campo social e mediático, num dado espaço e tempo (Pinto, 2011), não fica imune aos tempos de mudança e de incerteza que caracterizam a sociedade e os media (Santos, 2006).

As sucessivas opções de política pública sobre o modelo de serviço público de rádio e televisão refletem, em parte, opções ideológicas pré-existentes e o poder de influência que determinadas elites detêm e exercem junto dos sistemas político e económico. O tema RTP assume, assim, uma natureza simbólica, mobilizadora de outros significados, nomeadamente, de opções ideológicas sobre o papel do Estado na sociedade e na economia. Neste contexto, a ideia da privatização da RTP é utilizada como uma estratégia simbólica de afirmação política (Conde, 2013), assimilada a uma estratégia de representatividade dos agentes políticos, e de convencimento da opinião pública e dos demais atores políticos.

Pela importância que a rádio e a televisão têm para a sociedade, designadamente, a salvaguarda de princípios fundamentais como o pluralismo informativo e a diversidade cultural, bem como a prossecução de objetivos de interesse geral tais como a promoção da qualidade do discurso público e o desenvolvimento social, afigura-se pertinente analisar as opções políticas sobre o modelo de serviço público de rádio e televisão em Portugal, designadamente, no que concerne as modalidades de financiamento, modelo de governação e de prestação de contas.

\section{Objetivos \\ e metodologia}

O presente artigo tem por objeto a análise das opções de política pública em torno do modelo de financiamento, governação e prestação de contas do serviço público de rádio e televisão em Portugal. O intervalo temporal da investigação situa-se entre 2003, ano em que é aprovado o novo modelo de financiamento da RTP, e o último 
Tabela 1 | Etapas do modelo

de financiamento da RTP

Fonte: Autor, Carvalho (2009).

\begin{tabular}{ll}
\hline Anos & Etapas \\
\hline$(1957-1991)$ & Financiamento misto (taxa e publicidade) \\
$(1991-2003)$ & Abolição da taxa e crise de financiamento \\
$(2003-2013)$ & Financiamento tripartido (CAV, indemnização compensatória, publicidade) \\
$(2014-\ldots)$. & Reforma do modelo de financiamento (CAV, receitas comerciais) \\
\hline
\end{tabular}

justifica-se, a contrario, pelo facto de os mercados audiovisuais de países com mais população beneficiarem de economias de escala em virtude da sua dimensão (Picard, 2011: 45), algo que um país de pequena ou média dimensão como Portugal, com cerca de 10,5 milhões de habitantes, não possui, daí a comparação com países de pequena dimensão.

A comparação de Portugal com outas experiências europeias congéneres é relevante, pois permite contextualizar a realidade nacional no âmbito da família dos países da União Europeia. No entanto, importa ter presente que não existe um modelo ideal de financiamento, já que cada país tem a sua especificidade social, cultural e política (Picard, 2006).

Na presente investigação é ainda abordado o modelo de governação e de prestação de contas do operador de serviço público. Trata-se, no fundo, de compreender qual é o modelo de designação dos dirigentes do operador de serviço público e quais as modalidades previstas para a supervisão, inter-relação e prestação de contas da RTP perante o Estado, cidadãos e demais agentes do sistema de media.
A partir de um conjunto de dados secundários, designadamente, legislação e documentos (Observatório Europeu do Audiovisual e Rádio e Televisão de Portugal), a investigação, situada na interseção entre as áreas científicas de Economia Política e Políticas da Comunicação (Sousa, 2011: 397), pretende alcançar resposta para as seguintes questões: qual é a tendência evolutiva do modelo de financiamento da RTP? Quais são as características essenciais do modelo de governação da RTP? Qual é o modelo de prestação de contas da RTP?

\section{Etapas do modelo de financiamento da RTP}

O financiamento da RTP, desde o início regular das emissões televisivas, em 1957, até ao final de 2013, compreende quatro grandes etapas (Tabela 1).

O modelo inicial, que vigorou de 1957 a 1991, caracteriza-se por uma forma de financiamento misto, assente maioritariamente em receitas provenientes da denominada 'taxa de televisão', prevista no Decreto-Lei n. ${ }^{\circ}$ rar países com pequena dimensão 


\begin{tabular}{lccc}
\hline Ano & C.A.V & I.V.A 6\% & C.A.V + I.V.A \\
\hline $2003^{*}$ & 1,600 & 0,096 & 1,696 \\
2004 & 1,600 & 0,096 & 1,696 \\
2005 & 1,630 & 0,098 & 1,728 \\
2006 & 1,670 & 0,100 & 1,770 \\
2007 & 1,710 & 0,103 & 1,813 \\
2008 & 1,710 & 0,103 & 1,813 \\
2009 & 1,750 & 0,105 & 1,855 \\
2010 & 1,740 & 0,104 & 1,844 \\
2011 & 2,250 & 0,135 & 2,385 \\
2012 & 2,250 & 0,135 & 2,385 \\
2013 & 2,250 & 0,135 & 2,385 \\
\hline
\end{tabular}

Tabela 2 | Contribuição para o Audiovisual 2003/2013 (Euros)

Fonte: Diário da República

* setembro a dezembro de 2003

40341, de 18 de outubro de 1955, que estabeleceu as bases da concessão de serviço público para a RTP e das receitas da publicidade. Como fontes adicionais de financiamento cabe referir o recurso a aumentos do capital social da RTP, verificados em 1958 e 1961, detendo o Estado cerca de 60\% do capital em dezembro de 1975, data em que se verifica a nacionalização da empresa. Desde a fundação da RTP, em que o Estado detinha uma participação de um terço do capital, até ao período da nacionalização, o Estado triplicou a sua participação no capital social da concessionária (Carvalho, 2009: 343).

O modelo de sustentabilidade económico-financeira da RTP, assente no regular crescimento do número de espetadores e das receitas da taxa de televisão e da publicidade, entra em erosão a partir do 25 de Abril de 1974. Carvalho (2009: 341- 43) identifica como fatores explicativos do início da crise financeira da RTP o aumento significativo das despesas com o pessoal, os elevados níveis de inflação, as sucessivas atualizações do valor da taxa sempre abaixo dos valores da inflação anual, a crise no mercado publicitário, o aumento das despesas de funcionamento e a instabilidade vivida na empresa, com sucessivos conselhos de gerência.

A segunda etapa do modelo de financiamento da RTP inicia-se com a extinção da 'taxa de televisão', concretizada com a publicação do Decreto-Lei n. $53 / 91$, de 26 de janeiro de 1991. A conjugação da abolição da taxa no início de janeiro de 1991, com a abertura do mercado publicitário televisivo à SIC e TVI, a partir, respetivamente, de outubro de 1992 e fevereiro de 1993, provocaram importantes modificações no modelo de financiamento da RTP (Carvalho, 2009: 360). A RTP atravessa, então, um grave período de crise financeira. Nesta segunda fase do modelo de financiamento da RTP e para fazer face à situação de crise financeira que o operador público atravessa, o Estado recorre a vários expedientes, nomeadamente a injeções de capital.

Em 2003, com a publicação da Lei n. ${ }^{\circ} 30 / 2003$, de 22 de agosto, é aprovado o novo modelo de financiamento da RTP. Nesta terceira etapa do modelo de financiamento do serviço público, a RTP passa a ser financiada através de uma nova fonte de receita, a contribuição para o audiovisual, bem como através de indemnizações compensatórias e das receitas comerciais.

No que respeita a nova fonte de financiamento da RTP - a contribuição para o audiovisual, que incide sobre o fornecimento de energia elétrica, sendo devida mensalmente pelos respetivos consumidores -, o valor mensal é atualizado à taxa anual de inflação, através da Lei do Orçamento do Estado (artigo 4..$^{\circ}$ da Lei n. ${ }^{\circ} 30 / 2003$, de 22 de agosto). Conforme consta na Tabela 2 , o valor da contribuição para o audiovisual foi inicialmente estabelecido em $€$ 1,69 (IVA incluído), para o período compreendido entre 2003 e 2004, e foi sucessivamente aumentando, exceto no ano de 2010, com uma redução de $€ 0,01$ relativamente ao ano transato, atingindo em 2013 o valor de $€ 2,38$ (IVA incluído). Na proposta de Orçamento do Estado para 2014, prevê-se um aumento de 26 cêntimos, passando o valor para 2,65 euros por mês.

Ainda para melhor enquadramento da evolução do modelo de financiamento da RTP, acrescente-se que a 21 de agosto de 2003, os operadores 
Tabela 3 | Rendimentos Operacionais da RTP 2003/2012 (Milhões €)

Fonte: RTP (2004, 2005, 2006, 2007, 2008, 2009, 2010, 2011, 2012, 2013) $\begin{array}{llllllllll}2003 & 2004 & 2005 & 2006 & 2007 & 2008 & 2009 & 2010 & 2011 & 2012\end{array}$

\begin{tabular}{lcccccccccc}
\hline Rendimentos Operacionais (1+2+3) & 230,2 & 261,7 & 266,1 & 292,1 & 314,9 & 298,4 & 305,9 & 308,6 & 317,1 & 259,0 \\
(1) Fundos Públicos & 165,8 & 194,1 & 200,5 & 224,3 & 240,3 & 227,5 & 234,6 & 230,6 & 240,1 & 211,0 \\
Indemnização Compensatória & 98,7 & 120,4 & 120,8 & 124,0 & 125,9 & 117,5 & 119,3 & 121,1 & 89,0 & 73,2 \\
Contribuição Audiovisual & 67,1 & 73,7 & 79,7 & 100,3 & 114,4 & 110,0 & 115,3 & 109,6 & 151,1 & 137,8 \\
(2) Receitas Comerciais & 64,4 & 67,6 & 65,6 & 67,8 & 74,6 & 70,9 & 69,7 & 75,8 & 60,3 & 46,3 \\
Publicidade & 48,7 & 50,5 & 47,7 & 48,1 & 54,2 & 51,5 & 48,6 & 49,9 & 39,6 & 26,4 \\
Distribuição Cabo & n.d. & n.d. & n.d. & n.d. & n.d. & n.d. & 11,8 & 14,0 & 13,7 & 14,7 \\
Distribuição e Multimédia & n.d. & n.d. & 8,8 & 10,1 & 10,8 & 11,1 & n.d. & n.d. & n.d. & n.d. \\
Prestação Serviços Técnicos & n.d. & n.d. & n.d. & n.d. & n.d. & n.d. & 5,0 & 3,0 & 4,0 & 2,5 \\
Venda Conteúdos & n.d. & n.d. & n.d. & n.d. & n.d. & n.d. & 0,9 & 6,6 & 0,8 & 0,6 \\
Outras receitas & 15,7 & 17,1 & 9,1 & 9,6 & 9,6 & 8,3 & 3,4 & 2,3 & 2,2 & 2,1 \\
\hline (3) Outros Rendimentos e Ganhos & n.d. & n.d. & n.d. & n.d. & n.d. & n.d. & 1,6 & 2,2 & 16,7 & 1,7 \\
\hline
\end{tabular}

televisivos RTP, SIC e TVI celebram um Protocolo, alterado a 15 de fevereiro de 2005, nos termos do qual, a partir de 1 de setembro daquele ano, o tempo de publicidade na RTPl fica reduzido em $50 \%$ (6 minutos por hora), comparativamente ao limite horário de inserção de publicidade previsto para os operadores televisivos comerciais (12 minutos). No $2 .^{\circ}$ canal de serviço público (RTP 2), não é permitida a inserção de publicidade comercial. Nesse mesmo ano, o Estado e a RTP celebraram um Acordo de Reestruturação Financeira nos termos do qual as receitas de publicidade da RTP revertem para o pagamento da dívida acumulada.

Relativamente aos rendimentos operacionais da RTP no período compreendido entre 2003 e 2012 , e tendo presente os valores constantes na Tabela 3, cabe salientar o aumento dos rendimentos entre 2003 e 2007 , ano em que a RTP regista um resultado de 314,9 milhões de euros. Nesse período (2003/2007), os rendimentos operacionais subiram $36,79 \%$, os fundos públicos 44,93\%, e as receitas comerciais $15,84 \%$.
No ano de 2008, regista-se uma quebra nos rendimentos operacionais da RTP (298,4 milhões de euros), o que representa uma variação negativa de 5,24\% face ao valor de 2007, mas ainda assim superior ao valor de 2006. Idêntico cenário para a variação negativa dos fundos públicos e das receitas comerciais em 2008, relativamente a 2007 , respetivamente, $5,33 \%$ e 4,96\%, ficando ambos acima do valor de 2006.

No período subsequente, de 2009 a 2012, cabe salientar a tendência de evolução negativa dos indicadores económicos da RTP. Os rendimentos operacionais registaram uma variação negativa de 15,33\%, bem como os fundos públicos (-10,06\%), a par de uma quebra acentuada das receitas comerciais $(-33,57 \%)$.

A tendência de evolução negativa dos indicadores económicos da RTP nos últimos quatro anos coloca a empresa numa situação financeira delicada. Se nos concentrarmos na análise da evolução dos rendimentos entre 2011 e 2012 (Tabela 3), verificamos que os rendimentos operacionais da RTP decresceram 18,32\%, tendo para o efeito contribuído a redução dos fundos públicos, em cerca de $12 \%$, e das receitas comerciais, em $23,2 \%$.

A quarta e última etapa do modelo de financiamento da RTP consiste na eliminação das indemnizações compensatórias a partir do final de 2013. De acordo com o Orçamento de Estado para 2014, a RTP terá como fontes de rendimento a Contribuição para o Audiovisual, cujo valor sobe para 2,65 euros por mês, e as receitas comerciais.

\section{O financiamento da RTP no contexto da união europeia}

A partir de dados coligidos pelo Observatório Europeu do Audiovisual (European Audiovisual Observatory, 2012), respeitantes ao financiamento dos operadores de serviço público no ano de 2011, e optando por comparar Portugal com outros países da União Europeia cuja população não excede os 11 milhões de habitantes, sistematizou-se um conjunto de indicadores (Tabela 4) sobre o montante total do financiamento público, o volume total das receitas dos operadores públicos 


\begin{tabular}{lllll}
\hline País & $\begin{array}{l}\text { Financiamento público } \\
\text { (Milhões Euros) }\end{array}$ & $\begin{array}{l}\text { Total Receitas } \\
\text { (Milhões Euros) }\end{array}$ & $\begin{array}{l}\text { Peso do Financiamento } \\
\text { Público nas Receitas (\%) }\end{array}$ & $\begin{array}{l}\text { Financiamento público } \\
\text { p/ habitante (Euros) }\end{array}$ \\
\hline Áustria & 584,7 & 991,5 & 59,0 & 69,5 \\
Bulgária & 59,9 & 64,8 & 92,4 & 8,2 \\
Chipre & 31,7 & 36,9 & 85,9 & 36,8 \\
Dinamarca & 471,7 & 828,8 & 56,9 & 84,5 \\
Eslováquia & 116,0 & 122,5 & 94,7 & 21,5 \\
Eslovénia & 89,1 & 130,1 & 68,5 & 43,3 \\
Estónia & 25,0 & 28,3 & 88,3 & 18,7 \\
Finlândia & 415,4 & 437,1 & 95,0 & 76,9 \\
Hungria & 222,2 & 310,9 & 71,5 & 22,4 \\
Irlanda & 183,6 & 350,9 & 52,3 & 40,1 \\
Letónia & 15,8 & 22,2 & 71,2 & 7,7 \\
Lituânia & 11,6 & 18,9 & 61,4 & 3,9 \\
Malta & 2,5 & 9,0 & 27,8 & 6,0 \\
Portugal & 240,1 & 317,1 & 75,7 & 22,8 \\
República Checa & 329,0 & 387,5 & 84,9 & 31,3 \\
Suécia & 753,8 & 789,0 & 95,5 & 79,5 \\
\hline
\end{tabular}

Tabela 4 | Financiamento do serviço público na UE (2011) (Países $\leq 11$ Milhões habitantes) Fonte: European Audiovisual Observatory (2012) e o peso percentual do financiamento público e, por fim, o montante anual do financiamento público por habitante.

Da leitura dos dados constantes na Tabela 4, constata-se que o montante total do financiamento público da RTP em 2011 (240 milhões de euros), que representa cerca de 75 por cento do valor total das receitas da empresa, está longe dos valores praticados nos países do norte da Europa, designadamente, a Suécia, Dinamarca e Finlândia, respetivamente, com 753 , 471 e 415 milhões de euros de financiamento público em 2011.

Se atendermos à proposta de Hallin e Mancini (2010: 24-25) de classificação de sistemas de media, que os autores designam por "tipos ideais", identificamos um traço comum e distintivo dos países que pertencem ao denominado Modelo Corporativista Democrático, que predomina no Norte do continente europeu e onde se incluem os três países anteriormente referidos, que consiste no reconhecimento e valorização do papel do serviço público de rádio e televisão para o desenvolvimento da sociedade e para a salvaguarda da democracia, independentemente dos círculos políticos de governação.

Em contraponto, se tivermos em consideração as características culturais e políticas dos países incluídos no denominado Modelo Pluralista Polarizado (Hallin e Mancini, 2010), que prepondera nos países mediterrânicos e no Sul da Europa, incluindo Portugal, constatamos, no caso deste último, a inexistência de estabilidade na definição política de um modelo para o serviço público, com os inerentes reflexos no grau de alocação de fundos públicos para o seu financiamento.

Prosseguindo a análise comparativa dos dados da Tabela 4, e em linha com as conclusões anteriormente apontadas, cabe salientar que Portugal, com uma população cerca de 10 milhões e quinhentos mil habitantes (segundo a Eurostat, a 1 de janeiro de 2012), regista um valor de financiamento público anual por habitante inferior ao praticado nos países do norte do continente europeu: a importância anual de 22 euros e oitenta cêntimos por habitante em Portugal, contrasta significativamente com o financiamento público por habitante verificado na
Dinamarca $(84,5 €)$, Suécia $(79,5 €)$ e Finlândia $(76,9 €)$.

\section{Modelo de governação \\ e prestação de contas}

O modelo de governação da RTP, desde a sua fundação em 1955, foi pautado pela influência decisiva do Governo (Carvalho, 2009: 249) "na estrutura e no quotidiano da empresa". O fim da ditadura, com o 25 de Abril de 1974, e a nacionalização da empresa, em dezembro de 1975, não implicaram uma mudança significativa do modelo de governação da RTP. No período imediato pós-revolução não foram assegurados mecanismos de salvaguarda da independência da RTP face ao poder político, verificando-se inclusive (Carvalho, 2009: 256) "a sucessiva formação de cadeias hierárquicas de controlo político".

A instabilidade que se verificou na vida societária da RTP, palco de sucessivas mudanças na estrutura dirigente da empresa e nas direções de programas e de informação, acompanhando o frenesim dos ciclos políticos de governação, não contribuiu para 


\begin{tabular}{|c|c|c|}
\hline & Entidade & Competências \\
\hline & Parlamento & $\begin{array}{l}\text { Audição anual, ou sempre que necessário, dos membros do conselho de administração da RTP } \\
\text { e dos responsáveis pela programação e informação (Lei n. }{ }^{\circ} 8 / 2007 \text {, de } 14 \text { de fevereiro). }\end{array}$ \\
\hline & ERC - Entidade & Parecer prévio e vinculativo sobre a nomeação e destituição dos responsáveis pela \\
\hline & Reguladora para a & programação e informação. \\
\hline & Comunicação Social & $\begin{array}{l}\text { Parecer prévio e não vinculativo sobre os contratos de concessão de serviço público de rádio e } \\
\text { televisão, bem como das respetivas alterações. }\end{array}$ \\
\hline & & Auditorias anuais à execução dos contratos de concessão (Lei n. ${ }^{\circ} 53 / 2005$, de 8 de novembro). \\
\hline & Direção-Geral do & Orientações estratégicas destinadas ao setor empresarial do Estado (Resolução do Conselho \\
\hline & Tesouro e Finanças & de Ministros n. ${ }^{\circ} 70 / 2008$, de 27 de março de 2008). \\
\hline bela $5 \mid$ Modelode Prestac̃̃ & Conselho de opinião & $\begin{array}{l}\text { Parecer não vinculativo sobre planos de atividades e orçamento, relatório e contas, } \\
\text { cumprimento da missão, propostas de contratos de concessão. }\end{array}$ \\
\hline de Contas da RTP & & $\begin{array}{l}\text { Parecer vinculativo sobre pessoas indigitadas para os cargos de provedor do telespetador e de } \\
\text { provedor do ouvinte (Lei } n .^{\circ} 8 / 2007 \text {, de } 14 \text { de fevereiro). }\end{array}$ \\
\hline Fonte: Autor & Provedores do ouvinte & Mediação entre os públicos e os profissionais da RTP. \\
\hline & e do telespetador & Pareceres sobre queixas e sugestões. \\
\hline & & Relatório anual. \\
\hline & & Programa semanal (Lei n. ${ }^{\circ} 8 / 2007$, de 14 de fevereiro). \\
\hline
\end{tabular}

uma cultura de responsabilização da gestão do serviço público (Sena, 2011: 29).

A partir de 1992, com a Lei n. ${ }^{\circ}$ 21/92 (Estatutos da RTP), foi institucionalizado o Conselho de Opinião da RTP, representativo de diversos setores da sociedade mas sem parecer vinculativo sobre a nomeação e exoneração dos gestores da concessionária, com exceção do período entre 1998 e 2002 (Lei n. ${ }^{\circ}$ 31-A/98), e foi atribuída aos diretores das respetivas áreas a responsabilidade exclusiva pela seleção e conteúdo da programação e da informação. No ano de 2002, com a alteração da Lei da Televisão (Lei n. ${ }^{\circ}$ 18-A/2002), foi introduzido o princípio da inamovibilidade dos gestores da RTP, salvo casos excecionais tipificados na lei.

A partir de 2002, a entidade reguladora competente de então, a Alta Autoridade para a Comunicação Social, emite parecer vinculativo sobre a nomeação e exoneração dos diretores de programas e informação. Tal competência transita para a ERC - Entidade Reguladora para a Comunicação Social - em 2005. Com a Lei n. ${ }^{\circ}$ 8/2007 (Reestruturação da concessionária do serviço público de rádio e televisão), é estabelecido o princípio do acompanhamento parlamentar do trabalho efetuado pelos gestores e diretores de programas e de informação da RTP.

De forma sintética, e tendo presente o quadro normativo vigente (novembro de 2013), identificamos de seguida (Tabela 5), as entidades que intervêm no processo de prestação de contas da RTP, enquanto concessionária do serviço público de rádio e televisão, junto do Estado e dos cidadãos.

Tendo presente as competências efetivas das diversas entidades (Tabela 5) envolvidas no processo de prestação de contas da RTP, e salientando que o Governo designa livremente o Conselho de Administração, o qual, por seu turno, nomeia os diversos diretores da empresa, embora a designação dos diretores de informação e de programas esteja dependente de um parecer vinculativo da Entidade Reguladora para a Comunicação Social, considera-se o modelo de governação da RTP como governamentalizado.

Consequentemente, e na esteira do pensamento de Jakubowicz (2008 ${ }^{\mathrm{b}}$ : 108), interpretamos o modelo da RTP à luz do princípio do "paralelismo sistémico", segundo o qual, o sistema político de um país é transposto para o modelo de governação do operador de serviço público. Na perspetiva do autor (2008 ${ }^{\mathrm{b}}$ : 108), o fator decisivo não é tanto a intervenção do poder político no serviço público, por exemplo, na designação de cargos dirigentes, mas sim a qualidade de tal relacionamento, ou seja, a cultura política subjacente a tal conduta.

Importa, assim, repensar o modelo de governação e de prestação de contas da RTP. Para o efeito, será útil o recurso à lente crítica do conceito de governance proposto por Hanretty (2011: 165-166), segundo o qual importa ter em consideração a inevitabilidade da existência de interações entre o poder político e o operador de serviço público, nas suas componentes formais (legalistas) e reais (sociais).

No novo "contexto de hiperfragmentação da oferta" (Cádima, 2012), e tendo em consideração a necessidade de institucionalizar mecanismos de accountability do serviço público, de que são um exemplo os contratos de concessão (Coppens e Saeys, 2006: 281), afigura-se desejável que 
o lançamento de novos serviços de conteúdos seja precedido de uma avaliação do interesse público inerente.

Na reflexão sobre o novo modelo de governação da RTP, que se deseja mais focalizado no cidadão, enquanto destinatário último e causa justificante da própria existência da missão de serviço público, importa ter em consideração a necessidade de reforçar o papel do Provedor do ouvinte e do telespetador, o qual, a par do seu papel pedagógico (Gomes, 2010: 124), deverá ser encarado como uma instância promotora da autorregulação dos profissionais (Oliveira, 2007: 8-13), e agente impulsionador do aperfeiçoamento da qualidade e das responsabilidades inerentes à execução da missão de serviço público (Oliveira, 2009: 70).

\section{Conclusões}

A problemática da independência do serviço público de media, perante os poderes político e económico, está intrinsecamente relacionada com as questões do financiamento e do modelo de governação do operador de serviço público. O debate, na sua essência normativo, sobre o modelo ideal de serviço público, assume uma natureza simbólica, mobilizadora de outros significados, nomeadamente, de opções ideológicas sobre o papel do Estado na sociedade e na economia.

No caso português, assiste-se à tendência para uma redução progressiva dos rendimentos operacionais da RTP, com uma particular incidência nos últimos dois anos. A diminuição do financiamento público, que se agudizará com a eliminação das indemnizações compensatórias a partir de 2014, a par da tendência de redução das receitas comerciais, coloca a RTP numa situação complexa dado o amplo conjunto de obrigações de serviço público que está legal e contratualmente obrigada. Tendo em consideração o ambiente macroeconómico e o atual contexto político de Portugal, conclui-se que a redução do financiamento público da RTP se enquadra numa tendência mais vasta de reposicionamento do papel do Estado na economia.

No que concerne o modelo de governação da RTP, e atendendo ao critério da origem da designação dos dirigentes do operador público, considera-se o modelo vigente como governamentalizado, pese embora o escrutínio parlamentar, a intervenção da ERC na nomeação ou destituição dos diretores de informação e de programação, o papel fiscalizador do Conselho de Opinião e a função de mediação dos Provedores do telespetador e do ouvinte.

À luz do conceito de "paralelismo sistémico" proposto por Jakubowicz $\left(2008^{b}\right)$, segundo o qual o sistema político de um país é transposto para o modelo de governação do operador de serviço público, e atendendo ao caráter governamentalizado do modelo de governação da RTP, conclui-se pela necessidade de o modelo institucional de prestação de contas da RTP ser aperfeiçoado, de modo a garantir estabilidade e coerência na definição e prossecução dos seus objetivos programáticos. Para o efeito, deverá ser promovida uma nova cultura de relacionamento entre o poder político e os responsáveis pela gestão da RTP, a par da criação de mecanismos de prestação de contas mais direcionados para o cidadão. 


\section{Bibliografia}

Bardoel, J., \& Lowe, G. (2008). From Public Service Broadcasting to Public Service Media. The core challenge. In G. Lowe, \& J. Bardoel, (eds.), From Public Service Broadcasting to Public Service Media, Gotemburgo: Nordicom, 9-24.

Cádima, F. (2012). A Relegitimação do Serviço Público de Televisão e Portugal no contexto de hiperfragmentação da oferta. Anuário Internacional de Comunicación Lusófona, 10, Santiago de Compostela: AGACOM e LUSOCOM, 25-33.

Carvalho, A. (2009). A RTP e o Serviço Público de Televisão. Coimbra: Edições Almedina.

Collins, R. (2010). From Public Service Broadcasting to Public Service Communication. In G. Lowe (ed.), The Public in Public Service Media (pp. 53-66). Gothenburg: Nordicom.

Conde, N. (2013). A privatização da RTP como narrativa simbólica do poder político. Atas do $8 .^{\circ}$ Congresso da Associação Portuguesa de Ciências da Comunicação (SOPCOM), 2013. Comunicação Global, Comunicação e Tecnologia. Lisboa: Escola Superior de Comunicação Social.

Coppens, T., \& Saeys, F. (2006). Enforcing performance: new approaches to govern public service broadcasting. Media Culture Society, 28 (2), 261-284.

European Audiovisual Observatory (2012). Television, cinema, video and on-demand audiovisual services - The pan-european picture. In European Audiovisual Observatory (ed.), Yearbook 2012. Television, cinema, video and on-demand audiovisual services in Europe. Strasbourg: European Audiovisual Observatory.

Gomes, A. (2010). Provedoria da Rádio Pública Portuguesa. Reflexões sobre uma Experiência. Trajectos, 17, 121-124.

Hallin, D., \& Mancini, P. (2010). Sistemas de Media: Estudo Comparativo. Três modelos de comunicação e política. Lisboa: Livros Horizonte.

Hanretty, C. (2011). The Governance of Broadcasters in Small Countries. In G. Lowe \& C. Nissen (eds.), Small Among Giants. Television Broadcasting in Smaller Countries (pp. 163178). Gothenburg: Nordicom.
Humphreys, P. (1996). Mass Media and Media Policy in Western Europe. Manchester: Manchester University Press.

Iosifidis, P. (2011). The public sphere, social networks and public service media. Information, Communication \& Society, 14:5, 619-637.

Jakubowicz, K. (2008a). Public Service Broadcasting in the $21^{\text {st. }}$ Century. What chance for a new beginning? In G. Lowe, \& J. Bardoel, (eds.), From Public Service Broadcasting to Public Service Media (pp. 29-49). Gothenburg: Nordicom.

Jakubowicz, K. $\left(2008^{\mathrm{b}}\right)$. Finding the right place on the map: prospects for public service broadcasting in post-Communist countries. In K. Jakubowicz, \& M. Sukosd, (eds.). Finding the Right Place on the Map. Central and eastern european media change in a global perspective (pp. 101-124). Bristol: Intelect.

Lowe, G. \& Berg, C. (2013). The Funding of Public Service Media: A Matter of Value and Values. International Journal on Media Management, 15(2), 77-97.

Nord, L. \& Glowacki, M. (2010). 'Editors' introduction: Public Service Media 
in Central and Northern Europe. Does the State still matter? Central European Journal of Communication, 1, 7-20.

Oliveira, J. (2007). Relatório do Provedor do Telespectador (2006). RTP. Consultado a 1 de outubro 2013. Disponível em http://www.rtp.pt/ wportal/grupo/provedores.php .

Oliveira, J. (2009). Relatório do Provedor do Telespectador (2008). RTP. Consultado a 1 de outubro 2013. Disponível em http://www.rtp.pt/ wportal/grupo/provedores.php .

Picard, R. (2006). Financing public media: The future of collective funding. In C. Nissen, (ed.), Making a difference: Public service broadcasting in the European media landscape (pp. 183-196). Eastleigh: John Libbey Publishing.

Picard, R. (2011). Broadcast Economics, Challenges of Scale, and Country Size. In G. Lowe \& C. Nissen, (eds.), Small Among Giants. Television Broadcasting in Smaller Countries (pp. 43-56). Gothenburg: Nordicom.

Pinto, M. (2011). O debate sobre o serviço público de televisão em Portugal: algumas notas. Alicerces, 4, 255266.
Rádio e Televisão de Portugal (2004). Relatório e Contas 2003. Lisboa: RTP (policopiado).

Rádio e Televisão de Portugal (2005). Relatório e Contas 2004. Lisboa: RTP (policopiado)

Rádio e Televisão de Portugal (2006). Relatório e Contas 2005. Lisboa: RTP (policopiado).

Rádio e Televisão de Portugal (2007). Relatório e Contas 2006. Lisboa: RTP (policopiado).

Rádio e Televisão de Portugal (2008). Relatório e Contas 2007. RTP. Consultado a 1 de outubro 2013, em http://www.rtp.pt/wportal/grupo/ informacao_financeira/rc_anual. php .

Rádio e Televisão de Portugal (2009). Relatório \& Contas 2008. RTP. Consultado a 1 de outubro 2013, em http://www.rtp.pt/wportal/grupo/informacao_financeira/rc_anual.php .

Rádio e Televisão de Portugal (2010). Relatório \& Contas 2009. RTP. Consultado a 1 de outubro 2013, em http://www.rtp.pt/wportal/grupo/ informacao_financeira/rc_anual. php .

Rádio e Televisão de Portugal (2011). Relatório \& Contas 2010. RTP.
Consultado a 1 de outubro 2013. Disponível em http://www.rtp.pt/ wportal/grupo/informacao_financeira/rc_anual.php .

Rádio e Televisão de Portugal (2012). Relatório \& Contas 2011. RTP. Consultado a 1 de outubro 2013, em http://www.rtp.pt/wportal/grupo/ informacao_financeira/rc_anual. php .

Rádio e Televisão de Portugal (2013). Relatório \& Contas 2012. RTP. Consultado a 1 de novembro 2013, em http://www.rtp.pt/wportal/grupo/informacao_financeira/rc_anual.php .

Santos, S. (2013). Os Media de Serviço Público. [e-book] Covilhã: LabCom. Consultado a 1 de outubro 2013, em http://www.livroslabcom.ubi.pt/ pdfs/20130523-201305_silviocorreiasantos_mediaservicopublico.pdf . Santos, R. (2006). A Fonte Não Quis Revelar. Um estudo sobre a produção das notícias. Porto: Campo das Letras.

Sena, N. (2011). A Televisão por Dentro e por Fora. Coimbra: MinervaCoimbra.

Sousa, H. (2011). Economia Política dos Media: Origens e percursos, características nucleares e grandes temáticas. In Alicerces, 4: 383-407. 
Tambini, D. \& Cowling, J. (eds.) (2004). From Public Service Broadcasting to Public Service Communications. Institute for Public Research. Consultado a 1 de setembro 2013, em http://www.ippr.org/images/media/ files/publication/2011/05/public_ service_broadcasting_1296.pdf .

Torres, E. C. (2011). A Televisão e o Serviço Público. Lisboa: Fundação Francisco Manuel dos Santos. 